\title{
Análise da metodologia de ensino de ciências nas escolas da rede municipal de Recife
}

\author{
Kênio Erithon Cavalcante Lima \\ Simão Dias Vasconcelos
}

\section{Resumo}

professor de Ciências enfrenta uma série de desafios para superar limitações metodológicas e conceituais de formação em seu cotidiano escolar. Este trabalho buscou conhecer as principais dificuldades e metodologias de ensino de Ciências da rede pública municipal do Recife. Através de entrevista com 42 professores de 31 escolas, observamos que eles usam o livro didático como o recurso mais freqüente, diversificam suas estratégias de avaliação, e buscam, na medida do possível, desenvolver atividades extra-classe. Consideram como os assuntos mais difíceis de abordar os temas ligados à Física e Química, e como os assuntos que mais despertam a atenção de seus alunos os temas de Sexualidade e Meio Ambiente. Os professores citam o custo alto dos livros e revistas científicas e a falta de tempo como principais empecilhos para sua atualização pedagógica, e mantém fraca interação com universidades locais. Destaca-se a importância de uma educação continuada como mecanismo de atualização conceitual e metodológica.

Palavras-chave: Educação continuada. Escola pública. Perfil do educador. Avaliação. Recursos didáticos.

$$
\begin{gathered}
\text { Kênio Erithon Cavalcante Lima } \\
\text { Mestrando em Ensino das } \\
\text { Ciências, Universidade Federal } \\
\text { Rural de Pernambuco } \\
\text { Professor da Rede Estadual de } \\
\text { Educação de Pernambuco } \\
\text { keclima@ig.com.br } \\
\text { Simão Dias Vasconcelos } \\
\text { PhD, University of Oxford } \\
\text { Coordenador de Extensão } \\
\text { do Centro de Ciências } \\
\text { Biológicas, UFPE } \\
\text { simao@ufpe.br }
\end{gathered}
$$

methodology
Abstract

Analysis of

science

teaching

used by

teachers from

public schools

in Recife, Brazil

Science teachers face several challenges in order to overcome methodological and conceptual limitations in their daily profession. This study aimed at detecting the main difficulties and methodologies of Science teaching in public schools of the city of Recife, Brazil. 
By interviewing 42 teachers from 31 schools, we observed that they use textbooks as the most frequent resource, diversify their evaluation strategies and, as much as possible, develop outside didactic activities. They consider Chemistry and Physics to be the most difficult subjects, whilst the most interesting topics for the students are those related to Sexuality and Environment. The teachers cite the high cost of scientific books and journals and the lack of time as the main obstacles for their update on pedagogic practices, and have a very weak interaction with local universities. We stress out the importance of continuing education as a tool for overcoming limitations and providing continuing theoretical and technological knowledge.

Keywords: Continuing education. Public school. Educator's profile. Evaluation.

Didactic resources.

\section{Resumen}

\section{Análisis de la metodología de la enseñanza de ciencias en las escuelas de la red municipal de Recife, Brasil}

Los profesores de Ciencias enfrentan una serie de desafíos para superar limitaciones metodológicas y conceptuales de formación en su cotidiano profesional. Este estudio ha intentado conocer las principales dificultades y metodologías de enseñanza de las Ciencias de la red pública de la municipalidad de Recife, Brasil. A través de entrevistas con 42 profesores de 31 escuelas, observamos que ellos utilizan el libro didáctico como el recurso más frecuente, varían sus estrategias de evaluación y intentan, cuando es posible, desarrollar actividades extra clase. Ellos consideran como tópicos más difíciles la Química y la Física, mientras los que más despiertan interés del estudiante son aquellos relacionados al Medio Ambiente y la Sexualidad. Los profesores citan el elevado costo de libros y revistas científicas y la falta de tiempo como los mayores obstáculos para su actualización pedagógica y tienen una mínima interacción con las universidades locales. Destacamos la importancia de una educación permanente como mecanismo de actualización conceptual y metodológica.

Palabras clave: Educación continuada. Escuela pública. Perfil de lo educador. Evaluación. Recursos didácticos.

\section{Introdução}

\section{$O$ professor e as}

\section{exigências das novas abordagens educacionais}

O educador em Ciências tem sido historicamente exposto a uma série de desafios, os quais incluem acompanhar as descobertas científicas e tecnológicas, constantemente manipuladas e inseridas no cotidiano, e tornar os avanços e teorias científicas palatáveis a alunos do ensino fundamental, disponibilizandoas de forma acessível. Isto requer profundo conhecimento teórico e metodológico, e dedicação para (tentar) se manter atualizado no desempenho de sua profissão. Para muitos educadores, tais desafios são agravados por deficiências em suas licenciaturas - de universidades públicas ou privadas - pois a rapidez com que os conceitos se ampliam e surgem 
novas tecnologias faz com que a formação do professor possa ser considerada "obsoleta" poucos anos após sua graduação.

A realidade da educação brasileira, com superlotação nas salas de aula, desvalorização do profissional, e defasada estrutura física, metodológica e didática nas escolas instiga o docente a (se) questionar: "como" fazer e "com que" fazer educação, adequando-se à proposta projetada pelos parâmetros curriculares e pelo mercado de trabalho? Afinal, as escolas - especialmente da rede pública constituem-se de alunos marcantemente heterogêneos cultural e socialmente, o que requer do professor de Ciências o uso equilibrado de conceitos, de técnicas (competências) adequadas à comunidade; e dos seus instintos de educador (habilidades). Sem este equilíbrio, o papel da escola em reduzir diferenças sociais e promover igualdade entre alunos, independentemente de suas origens étnicas, sociais e culturais, bem como do nível de habilidades e predisposições inerentes do indivíduo (FOLLESDAL, 2000, apud HOLMESLAND, 2003), acaba não sendo concretizado.

Alunos do ensino fundamental da rede pública na maioria das vezes deparam-se com metodologias que nem sempre promovem a efetiva construção de seu conhecimento. Tampouco lhes são oferecidos mecanismos de compensação por defasagens sociais, que vão desde problemas de natureza familiar ao limitado acesso a livros, sites e outras fontes de conhecimento. Cabe ao educador em Ciências superar tais obstáculos, construindo possibilidades de mudança, ao estimular atividades que priorizem questões de Ciências, Tecnologia e Sociedade (CTS). Esta tarefa pressupõe unificar experiências e estratégias de ensino, para qualificar a educação desenvolvendo novas competências a serem aplicadas nas escolas, uma "busca que inclui desde a procura por cursos, treinamentos ou leituras, até uma troca constante de informação com colegas considerados mais competentes ou especialistas na área" (DIAS-DA-SILVA, 1998, p. 37). Certamente, não há o método ideal para ensinar nossos alunos a enfrentar a complexidade dos assuntos trabalhados, mas sim haverá alguns métodos potencialmente mais favoráveis do que outros (BAZZO, 2000).

A superação dessas dificuldades sustenta-se sobre dois alicerces: uma graduação solidamente fincada na construção de habilidades e competências, e uma oferta de formação permanente/contínua aos graduados, aumentando o contato das instituições de ensino básico com universidades e centros de pesquisa, estabelecendo laços de pesquisa/ conhecimento de interesse comum.

\section{Instrumentos de apoio didático}

Freqüentemente, ao trabalhar os conteúdos, os educadores deparam-se com frágeis instrumentos de trabalho, o que pode gerar dependência ao uso do livro didático. Krasilchik (2004, p. 184), assume postura crítica diante desta situação:

O docente, por falta de autoconfiança, de preparo, ou por comodismo, restringe-se a apresentar aos alunos, com o mínimo de modificações, o material previamente elaborado por autores que são aceitos como autoridades. Apoiado em material planejado por outros e produzido industrialmente, o professor abre mão de sua autonomia e liberdade, tornando-se simplesmente um técnico.

Como alternativas, o educador hoje dispõe da internet, experimentotecas, kits didáti- 
cos e de revistas científicas que oferecem atualização sobre os mais diversos temas científicos. Uma outra fonte, de grande relevância, é a formação continuada, necessária para a atualização do conhecimento e criação conjunta de novas metodologias de ensino.

Neste contexto de múltiplas exigências, como os professores de Ciências trabalham os conteúdos programáticos e estratégias de avaliação do conhecimento assimilado pelo aluno? Será que seguem as propostas dos $\mathrm{PCN}$, aplicando metodologias que fogem ao tradicionalismo, ou tendem a enfatizar propostas pedagógicas inadequadas para a formação do aluno? Quais as principais dificuldades para obtenção de outras fontes de conhecimento, além dos livros texto adotados? Como os professores de Ciências percebem a importância da educação continuada para aprofundar seu domínio de novos conceitos e tecnologias?

\section{Pertinência e objetivos da pesquisa}

Diante destas indagações, acreditamos que iniciativas de melhoria da qualidade de ensino devem ter como ponto de partida a caracterização do ensino per se; ou seja, conhecer o perfil do professor, suas dificuldades, metodologias utilizadas em sala de aula (ou fora dela), e as perspectivas de formação permanente. Partindo de nossa interação com professores de Ciências da rede pública, e de nossa formação em Biologia, escolhemos como objetivo da pesquisa caracterizar o perfil dos educadores de ciências da $5^{a}$ a $8^{a}$ séries do fundamental da Rede Municipal do Recife. Concentramos nosso estudo na análise de sua metodologia de trabalho, sua formação profissional, as fontes de atualização conceitual e suas perspectivas de educação permanente. Ao longo do estudo, priorizamos temas relacionados ao ensino de conceitos biológicos.

\section{Metodologia da pesquisa}

A pesquisa teve como público-alvo professores de Ciências do $3^{\circ} \mathrm{e} 4^{\circ}$ ciclos do ensino fundamental das escolas municipais de Recife - PE, com a concordância da Secretaria de Educação da Prefeitura Municipal do Recife. As entrevistas estruturadas foram conduzidas entre novembro de 2001 e março de 2002 pelo primeiro autor deste trabalho, e tiveram duração média de 20 minutos, após explicações iniciais sobre a natureza e objetivos da pesquisa. Foram entrevistados 42 professores de 31 das 35 escolas de ensino fundamental mantidas pela Prefeitura.

As perguntas eram em sua maioria de natureza objetiva, sendo cerca de $20 \%$ delas discursivas. Estas foram analisadas na proposta de avaliação qualitativa de Bardin (2004) e Silva e Azevedo (2005). O procedimento foi realizado com autorização dos diretores das escolas, e manteve-se o anonimato dos entrevistados ao longo do estudo. A entrevista estruturada com o auxilio de um questionário abrangeu dois eixos temáticos: a) o perfil socioeconômico e a formação profissional do professor; e b) a metodologia de ensino e avaliação em sala de aula. Buscouse caracterizar o perfil do docente através de questões sobre idade, formação acadêmica, tempo de exercício da profissão, faixa salarial, atividades profissionais complementares, fontes de informação em Ciências, acesso à internet e bibliotecas entre outros.

A metodologia de ensino e avaliação foi caracterizada pelos seguintes parâmetros: material didático utilizado, incluindo livro texto e fontes complementares, formas de trabalhar o conteúdo em sala de aula, atividades extraclasse, assuntos de maior dificuldade para o professor, tópicos que despertam maior inte- 
resse entre os alunos, sistema de avaliação, atividades complementares, entre outros.

\section{Resultados}

\section{Perfil socioeconômico e a formação profissional}

perfil dos professores revela uma predominância de mulheres $(60,0 \%)$ e de profissionais com curso superior concluído (88,1\%). Dentre estes, a maioria é graduada em Licenciatura em Ciências Biológicas $(85,7 \%)$, sendo as instituições de ensino superior de origem dos graduados as duas universidades públicas federais de Pernambuco $(41,7 \%)$, instituições particulares/comunitárias $(55,5 \%)$ e estaduais $(2,8 \%)$.

Observou-se que $31,0 \%$ dos professores têm menos de 35 anos, 33,3\% possuem entre 36 e 45 anos, e $35,7 \%$ possuem mais de 45 anos. Quase a metade dos professores $(45,0 \%)$ possui significativa experiência na docência, ensinando há pelo menos 15 anos. A faixa salarial da maioria dos professores é, conforme esperada, baixa: $88,1 \%$ recebem em média até 8 sa- lários mínimos (valores de 2002). Devido a isto, a maioria dos professores $(64,3 \%)$ afirma necessitar trabalhar em mais de uma escola.

\section{Livros-texto e outras fontes de informação/ atualização}

Os livros adotados oficialmente pela Prefeitura da Cidade do Recife durante a pesquisa foram "Os Seres Vivos", de Carlos Barros e Wilson Roberto Paulino (2001), e "Vivendo Ciências", de Maria de La Luz e Magaly Terezinha dos Santos (2002), dos quais o primeiro foi alvo de maior aprovação pelos professores. Os professores, no entanto, declararam utilizar outros livros-texto além do adotado pela rede de ensino como fontes complementares, acrescidos de materiais didáticos de sua própria autoria. No entanto, cerca de $43,0 \%$ dos entrevistados afirmaram ter grandes dificuldades em obter maior aceno de material de apoio didático, as quais incluem falta de tempo $(67,0 \%)$, ausência de bons textos científicos em Português $(17,0 \%)$, e escassez de bibliotecas especializadas (16,0\%).

\section{Tabela 1 - Nível de satisfação dos professores da Rede Municipal de Ensino do Recife em relação aos livros didáticos adotados pela escola ( $\mathrm{N}=42)$ (mais de uma resposta possível)}

\begin{tabular}{|l|l|}
\hline \multicolumn{2}{|c|}{ SATISFEITOS - (N = 27) } \\
\hline Comentários & Freqüência \\
\hline Linguajar adequado -02 & $7,4 \%$ \\
\hline Não fizeram comentários - 25 & $92,6 \%$ \\
\hline \multicolumn{2}{|c|}{ INSATISFEITOS - (N = 15) } \\
\hline Comentários & Freqüência \\
\hline Não houve atualização no conteúdo - 02 & $15,3 \%$ \\
\hline Não é detalhado (pouco didático) - 09 & $69,2 \%$ \\
\hline Não trabalha bem os exercícios, poucas atividades com gráficos e figuras - 04 & $30,8 \%$ \\
\hline Poucas atividades práticas - 02 & $15,3 \%$ \\
\hline Falta de abordagem de conteúdos para a Região Nordeste - 03 & $23,0 \%$ \\
\hline
\end{tabular}


Como fontes complementares de informação em Ciências, 74,0\% dos professores afirmam ler revistas de divulgação científi$\mathrm{ca} /$ educacional, especialmente "Superinteressante" (55,0\% dos entrevistados); "Nova Escola" (36,0\%), "Ciência Hoje" (33,0\%) e "Galileu" (14,0\%). Entre os que afirmaram não possuir o hábito de ler revistas de divulgação, 90,0\% indicaram a falta de tempo como o principal motivo, $20 \%$ atribuíram a dificuldade de obtenção de tais revistas ao seu custo elevado. Ainda como fontes de informação sobre Ciências/ Educação, a maioria dos docentes $(57,0 \%)$ afirmou não freqüentar regularmente bibliotecas especializadas. Questionados sobre suas fontes de informação específicas em ciências, os professores manifestaram desconhecimento sobre periódicos científicos, uma vez que nenhum soube citar qualquer revista científica indexada nacional ou internacional em suas respectivas áreas de atuação/interesse.

Em relação à internet, observou-se que
$81 \%$ dos professores têm acesso a esta ferramenta, principalmente em casa (74\%), ou na escola (30\%). A internet é pouco usada para desenvolver pesquisas sobre Ciências e/ou Educação; como também, elaborar aulas e outras atividades por $55 \%$ dos professores entrevistados.

Quanto aos recursos mantidos pela UFPE que poderiam contribuir para a atualização profissional de professores de Ciências, os entrevistados destacaram principalmente: laboratórios $(83,4 \%)$, cursos e palestras $(83,4 \%)$, experimentotecas $(69,0 \%)$, coleções zoológicas $(64,3 \%)$, herbários $(38,0 \%)$.

\section{Assuntos abordados: dificuldades e interesses}

Ao serem questionados sobre quais assuntos despertam maior interesse dos alunos da $5^{a}$ à $8^{a}$ do fundamental, os temas ligados à sexualidade e reprodução são os que mais prendem a atenção dos alunos (Tabela 2).

Tabela 2: Assuntos que despertam maior interesse pelos alunos da 5q, 6q, 7qa e 8a séries, segundo professores de Ciências da Rede Municipal de Ensino de Recife ( $N=42)$.

\begin{tabular}{|c|l|c|c|}
\hline SÉRIE & ASSUNTO & No DE CITAÇÕES & PERCENTAGEM (\%) \\
\hline \multirow{4}{*}{$5^{a}$} & Água e o ar & 11 & 26,2 \\
\cline { 2 - 4 } & Meio Ambiente & 10 & 23,8 \\
\cline { 2 - 4 } & Programa de Saúde & 08 & 19,0 \\
\hline \multirow{4}{*}{$6^{a}$} & Vertebrados & 18 & 42,8 \\
\cline { 2 - 4 } & Programa de Saúde & 04 & 9,5 \\
\cline { 2 - 4 } & Sexualidade & 04 & 9,5 \\
\hline \multirow{3}{*}{$7^{a}$} & Reprodução Humana & 19 & 45,2 \\
\cline { 2 - 4 } & Sexualidade & 09 & 21,4 \\
\cline { 2 - 4 } & Programa de Saúde & 02 & 4,8 \\
\hline \multirow{3}{*}{$8^{a}$} & Noções de Química & 19 & 45,2 \\
\cline { 2 - 4 } & Noções de Física & 11 & 26,2 \\
\cline { 2 - 4 } & Sexualidade & 06 & 14,3 \\
\hline
\end{tabular}


Quando indagados sobre quais assuntos sentem mais dificuldade em ensinar, os professores citaram principalmente Noções de Física (45\%) e de Química (24\%) (Fig. 1). Questionados so- bre os motivos para tais dificuldades, os entrevistados alegaram deficiências em sua formação profissional, na qual afirmam ter recebido uma base menos aprofundada sobre aqueles temas.

Figura 1 - Assuntos abordados no ensino fundamental $\left(5^{a}\right.$. a $8^{a}$. séries) que oferecem maiores dificuldades teóricas e metodológicas para os professores da Rede Municipal de Ensino de Recife ( $\mathrm{N}=42$ ) (mais de uma opção possível).

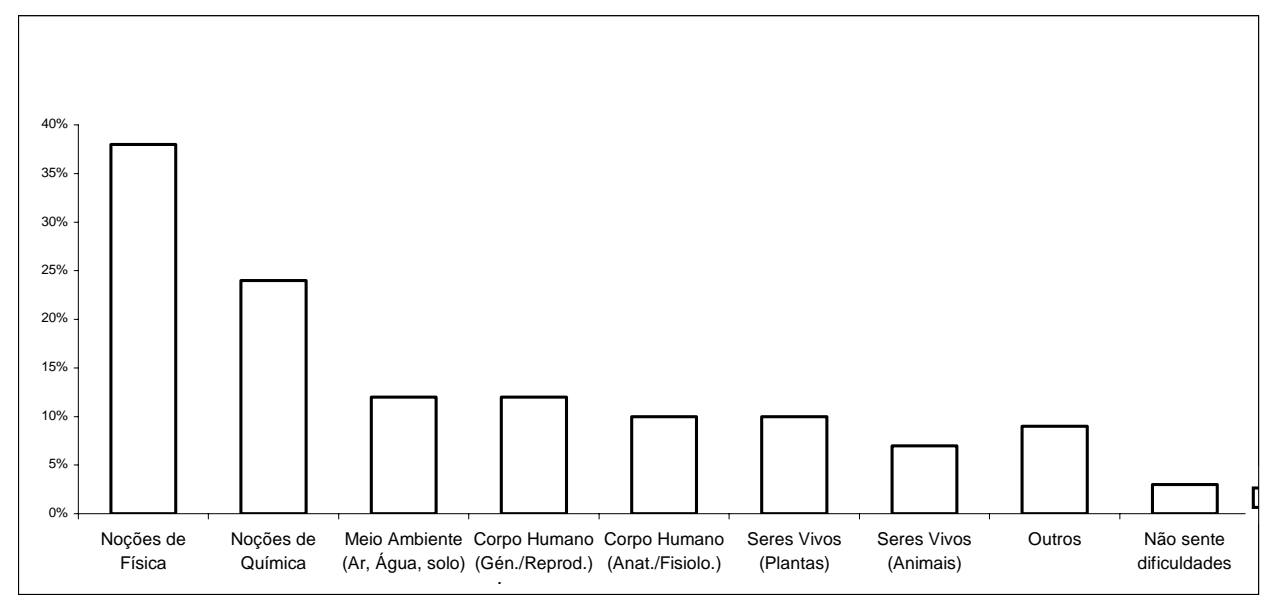

\section{Atividades intra e extra- classe e mecanismos de avaliação de aprendizagem}

Quando indagados sobre o material de apoio didático usado em sala de aula observou-se que livros (93\%) e vídeos (60\%) são os recursos mais utilizados. Curiosamente, o uso do computador já parece estar assumindo um papel relevante nas escolas públicas uma vez que $31 \%$ dos professores afirmaram utilizá-lo durante as aulas. Outros materiais citados incluem transparências (utilizadas por $24 \%$ dos professores) e revistas (7\%). Além da exposição oral "convencional", os professores declararam lan- çar mão de outros formatos, tais como organização de feiras de ciências (93\%), visitas a museus e parques (50\%), condução de experimentos (41\%), excursões didáticas (38\%), entre outros categorizados como atividades extra-classe. Apenas 5\% dos professores entrevistados afirmaram não utilizar nenhuma destas atividades.

A metodologia de avaliação mais freqüentemente utilizada pelos professores de Ciências baseia-se na avaliação escrita (mais de 90\% dos entrevistados). Tais avaliações consistem de questões discursivas sobre os tópicos apresentados ao longo do curso (90\% das respostas) e questões de múltipla escolha ("objetivas", aplicadas por $86 \%$ dos entrevistados). Percebem-se mudanças em 
direção a um estilo mais contínuo e diversificado de avaliação, baseado em critérios de participação do aluno nas atividades em sala de aula e fora dela. Cerca de 95\% dos professores entrevistados afirmam lançar mão de instrumentos de avaliação variada, que incluem a elaboração de relatórios pelos alunos das atividades extra-classe; pesquisas na internet, livros e revistas de divulgação científica, e desempenho em Feiras de Ciências, tendo este conjunto de atividades sido citado por $80 \%$ dos professores. Outra forma de avaliação utilizada inclui seminários (50\% das respostas).

Entre as propostas citadas pelos professores para compensar suas deficiências metodológicas, as mais freqüentes foram: maior interação UFPE/professores/alunos $(34,4 \%)$; trabalhos e cursos de atualização promovidos por instituições de ensino superior locais $(18,8 \%)$ (Tabela 3$)$.

Tabela 3: Comentários / perspectivas dos professores de Ciências da Rede Municipal de Ensino de Recife quanto ao produto gerado por esta pesquisa ( $N=42)$.

\begin{tabular}{|ll|}
\hline COMENTÁRIOS / CRÍTICAS - Número de citações & PERCENTAGENS \\
\hline $\begin{array}{l}\text { Que se tomem medidas concretas para resolver } \\
\text { problemas dos professores da rede pública - 6 }\end{array}$ & $18,8 \%$ \\
\hline $\begin{array}{l}\text { Maior interação das universidades com os professores } \\
\text { da rede pública e os alunos da rede municipal - 1 1 }\end{array}$ & $34,4 \%$ \\
\hline $\begin{array}{l}\text { Realização de palestras e experimentos nas escolas, } \\
\text { proporcionados pela universidade - } 4\end{array}$ & $12,5 \%$ \\
\hline $\begin{array}{l}\text { Maior flexibilidade para que os professores da rede } \\
\text { municipal possam fazer Pós-Graduação - 5 }\end{array}$ & $15,6 \%$ \\
\hline $\begin{array}{l}\text { Trabalhos e cursos de atualização promovidos } \\
\text { por Instituições de Ensino Superior locais - 6 }\end{array}$ & $18,8 \%$ \\
\hline $\begin{array}{l}\text { Maior pesquisa para desenvolver ferramentas, material didático } \\
\text { e outras formas de melhorar a qualificação do Ensino - 3 }\end{array}$ & $9,4 \%$ \\
\hline $\begin{array}{l}\text { Realizar capacitações nos finais de semana para oportunizar } \\
\text { aos que trabalham durante a semana - 05 }\end{array}$ & $15,6 \%$ \\
\hline Não realizaram comentários - 10 & $23,8 \%$ \\
\hline
\end{tabular}

\section{Discussão}

\section{A educação "tradicional" e suas limitações}

A análise da metodologia de ensino nas escolas recifenses revela que a educação tradicional ainda é adotada, resistindo e coexistindo com as novas propostas. Para Kruger (2003, p. 71),
O Modelo Didático Tradicional é caracterizado por concepções de ensino como uma transmissão/transferência de conhecimentos, por uma aprendizagem receptiva e por um conhecimento absolutista e racionalista. Destas deriva uma prática profissional que concebe os conteúdos de sala de aula como reprodução simplificada do conhecimento cien- 
tifico 'verdadeiro', transmitido verbalmente pelo professor (metodologias transmissivas), por um currículo fechado e organizado de acordo com uma lógica disciplinar e por uma avaliação classificatória e sancionadora.

Esta abordagem consta do trabalho dos educadores pesquisados, para os quais o livro didático é o principal instrumento de trabalho, em detrimento de atividades extras, como aulas práticas e projetos de pesquisa que explorem mais as habilidades cognitivas do aluno. Como ressalta Loguercio, Pino e Souza (2002), o livro didático tem significância nas construções curriculares, sendo muitas vezes o refúgio que acaba por definir o trabalho docente. As falhas dos livros didáticos têm sido alvo de diversas análises (SOUTO, 2003). Felizmente, significativas correções estão sendo propostas e adotadas, qualificando e adaptando nossos livros à necessidade do aluno/comunidade. Ainda assim, é necessário quebrar a dependência a este recurso, complementando-o com outras fontes de conhecimento/atualização para o docente, como livros e periódicos científicos.

Em parte por limitação de recursos didáticos, muitos professores sentem-se obrigados a sobrecarregar os alunos com exames periódicos de conhecimento, supervalorizando testes escritos, discursivos e objetivos, como mecanismos para aferir notas. Devido à sobrecarga de trabalho, aos educadores nem sempre resta tempo para testar e/ou construir outros mecanismos/critérios de avaliação. Além disso, há a cobrança para que se cumpra literalmente o conteúdo do livro, priorizando a quantidade de informações a ser repassada ao aluno. Exige-se do estudante abusiva memoriza- ção, sem valorizar o raciocínio e a aprendizagem por critérios que transcendam provas para documentação e atribuição de notas. Entretanto, em nosso público-alvo percebemos a preocupação em utilizar outras formas de avaliação, tais como seminários, pesquisas e a participação do aluno nas atividades que relacionam o cotidiano dos alunos e suas comunidades.

Processos avaliativos devem buscar, na concepção de Hadji (2001), integrar, trocar e negociar os interesses comuns entre os elementos participantes (avaliador e avaliado), retratando a realidade com uma compreensão que a ciência busca enfocar e contextualizar, dando mais significado à aprendizagem do aluno, valorizando o ofício da docência. $\bigcirc$ comentário de uma docente entrevistada ilustra bem as dificuldades envolvidas na avaliação:

Eu tento diversificar minhas ferramentas de avaliação [...] já fiz excursão didática com elaboração de relatório, observações no pátio da escola, debates [...] Mas sempre esbarro na falta de motivação da maioria dos alunos. Eles preferem coisas mais fáceis, como responder questionários com consulta no caderno ou no livro didático que usamos." (M.A.S., professora).

Para Hoffmann (2005, p. 91), "mediar a mobilização diz respeito à provocação do desejo de aprender e/ou criar a necessidade de aprender - talvez um dos nossos compromissos mais difíceis enquanto educadores".

Krasilchik (2004, p. 149-150) argumenta que no ensino das Ciências, e mais especificamente de Biologia, avaliações baseadas em práticas de laboratório e campo são escassas e ainda mais complexas. 
As dificuldades para elaborar uma prova prática são inúmeras e, possivelmente, por esta razão, raramente são feitas e, quando o são, limitam-se a verificar a capacidade que os alunos têm de manipular os instrumentos, sem aferir sua capacidade de realizar uma investigação. [...] Essas habilidades não podem ser medidas em provas escritas. É necessário colocar o aluno no laboratório realizando os experimentos para verificar realmente o que aprendeu e como se comporta frente a um problema concreto.

\section{O professor como agente integrador}

Um desafio imposto ao professor é aplicar práticas pedagógicas acompanhadas de práticas conceituais; ou seja, relacionar os conceitos à realidade do aluno, dando significado e importância ao assunto apresentado. Tal desafio requer a integração de disciplinas, conhecimentos específicos e qualificações humanas, como habilidades, competências, atitudes e valores. Neste sentido, percebemos que os entrevistados afirmam promover aulas de campo, com excursões e visitas a museus e parques como atividades extra-classe. Ainda, diversificam sua metodologia de aula ao utilizar vídeos, leituras de revistas e reportagens para discutir sobre temas do cotidiano dos educandos. Acreditamos que tais iniciativas sejam o começo de um diferencial metodológico, entendendo-se o educador não mais como detentor de todo o conhecimento, e sim como mediador nos processos de formação e desenvolvimento dos saberes prévios dos estudantes, conforme premissas dos PCN e lembrado por Pereira e Souza (2004, p. 193):
Os conteúdos devem ser tratados de forma globalizada, valorizando as experiências do cotidiano dos alunos, permitindo a relação entre teoria e prática, dando significado às aprendizagens realizadas na escola, possibilitando que estas sejam úteis na vida, no trabalho e no exercício da cidadania.

Para alcançar tais objetivos, incorporando-os às diretrizes pedagógicas das escolas, é importante que o professor tenha boa formação e motivação, e que esteja atualizado, como também consciente de seu papel social, cultural e político a desempenhar com e para seus alunos. Para Pereira e Souza (2004, p. 205),

Precisamos romper com a cultura da seletividade e da exclusão, atenuar posturas avaliativas classificatórias e evoluir para abordagens de ensino, de aprendizagem e de avaliação mais compatíveis com as necessidades dos alunos, procurando construir uma escola mais democrática e acessível a todos, comprometida com a transformação da realidade.

O educador começa a perceber que o conhecimento não brota apenas das instituições de ensino; mas que estas devem-se comportar como ponto focalizador dos conhecimentos científicos, culturais e pré-existentes aos alunos. Em contrapartida, a escola deve reconhecer as necessidades do educador, valorizando seu trabalho, inclusive oferecendo remuneração coerente com seu oficio e trabalho desempenhado. Afinal, anos de desvalorização da categoria docente, baixos salários e desprestígio em termos sociais desencadearam um fenômeno de descrença na qualidade acadêmica de professores em formação (TEDESCO, 2000). Jesus e Souza (2004, p. 45) reco- 
nhecem que "limitações nas condições de trabalho e o baixo nível remuneratório levam muitos professores a investir a sua necessidade de expansão e de formação em atividades fora da escola, profissionais comunitários ou familiares, empenhando-se o mínimo possivel na profissão docente". Registramos ainda o envolvimento dos docentes em outras instituições de ensino, como escolas particulares, além de ofícios distintos da educação, como efeito colateral dos baixos salários recebidos.

\section{A educação permanente de professores de Ciências}

Diferenças no tempo de conclusão dos estudos formais podem resultar em professores de Recife estão pouco familiarizados com novas tecnologias e atualizações de terminologia. Isto abre espaço para a discussão: como promover ações de educação permanente que respeitem as prioridades do educador e do educando? Vianna e Carvalho (2000) destacam a importância de o educador interagir com cientistas, ressaltando que muitos educadores não tiveram a oportunidade, durante sua formação, de ter contato com pesquisas de laboratório e campo. Ressalta, ainda, a importância de despertar no educador o desejo de gerar conhecimento científico. Caso não tenha acesso a laboratórios, o docente pode consultar publicações ou participar de eventos que discutam os avanços científicos de sua área de trabalho/interesse.

Entre os entrevistados, a interação com pesquisadores das IES - Instituições de Ensino Superior, é pífia. A leitura de artigos científicos específicos à educação ou das Ciências não é ainda um hábito difundido, tendo em vista que não souberam citar títulos de revistas cientificas, alegando custo elevado e pouco tempo para a leitura das mesmas. Tais respostas não se justificam totalmente nos dias de hoje, considerando-se a disponibilidade de textos científicos na internet. Sites como SciELO (Scientific Electronic Library On-line)', disponibilizam gratuitamente artigos completos de revistas de qualidade internacional. Neste ponto, consideramos que estão sendo sub-utilizados os recursos da Internet, tendo em vista que mais de $80 \%$ dos professores pesquisados afirmaram ter acesso a esta ferramenta. Curiosamente, este percentual contraria dados de Silva e Azevedo (2005), destacando que muitos professores da educação pública estadual não dispõem de computadores, mas gostariam de possuir.

Frazzon (2001) destaca a distância entre universidade e professores do ensino básico; e também ressalta que as instituições superiores podem ser uma via constante de atualização dos professores que, por sua vez, refletirão seus trabalhos na qualificação do ensino fundamental e médio. Neste contexto, a Universidade Federal de Pernambuco -UFPE, tem colaborado com instituições de ensino básico, abrindo suas portas para visitas a laboratórios, oferecendo tecnologia e conhecimento para professores e alunos do ensino médio e fundamental. Há ainda a participação de professores de escolas públicas e particulares em eventos de extensão realizados pelo Centro de Ciências Biológicas (CCB), os quais incluem Simpósios, cursos, oficinas, visitas técnicas e semanas de atualização.

Periodicamente, a UFPE disponibiliza espaço para ações de educação continua-

'Disponível em: <www.scielo.org.br>. 
da em parceria com outras instituições de ensino básico, incluindo visitas a coleções didáticas, laboratórios e herbários. Contribui ainda para a construção de experimentotecas e disponibiliza material biológico para exposições em feiras de ciências promovidas por escolas particulares e públicas locais. Por esse motivo, conhecer o perfil do professor é vital no momento de formular propostas para uma educação continuada que corresponda aos anseios do educador e às necessidades do sistema de ensino.

No nosso estudo, algumas colocações aproximaram-se das registradas por Kruger (2003, p. 78), em seu estudo envolvendo 28 professores do ensino básico, principalmente de Ciências, durante curso de especialização em Ensino de Ciências em Lajeado (RS), os quais

[...] queixaram-se da carga horária elevada e da 'falta de tempo para se atualizar e preparar aulas', manifestaram a necessidade de compartilhar idéias e angústias profissionais e de 'crescer dentro de seu trabalho', além de sentirem 'falta de estudos, de debates e de embasamentos'. Muitas vezes não sabem como 'lidar com questões disciplinares', pois gostariam de 'compreender as dificuldades dos alunos', 'tornar o conteúdo atrativo', 'aproximar conceitos da realidade' e discutir 'formas de avaliação'.

Os programas de atualização/formação permanente devem ter como ponto de partida as dificuldades detectadas em visitas às próprias escolas. Por exemplo, os professores de Ciências da Rede Municipal de Recife destacam que, por deficiência em sua formação, sentem dificuldades em trabalhar conceitos de Física e Química. Rela- tam ainda outros assuntos, talvez decorrentes das rápidas mudanças de conceito e abordagem e/ou pela complexidade de sua natureza, o que pode gerar insegurança em sala de aula, levando alguns simplesmente a dedicar menor atenção aos referidos temas. Destes assuntos, os mais citados incluem temas ligados ao meio ambiente e ao corpo humano.

Em contrapartida, relatam que os assuntos de maior "atratividade" para os alunos são os referentes à sexualidade, genética moderna e questões ambientais. Isto é compreensível, pois muitos alunos encontramse na puberdade, quando começam a descobrir suas próprias transformações corporais e emocionais. No entanto, percebe-se em Recife uma incrível carência de disciplinas (isoladas ou conjuntas), e materiais de apoio didático voltados para o ensino de Orientação Sexual como tema transversal, conforme orienta os PCN. Uma breve análise dos cursos de Licenciatura em Ciências Biológicas de Pernambuco revela que nenhum deles possui qualquer disciplina específica sobre Ensino de Sexualidade. No curso de Licenciatura da UFPE, tal disciplina não foi inserida na nova estrutura curricular por absoluta falta de professores interessados e/ou que se declaram "capazes". A defasagem de conhecimento sobre Genética Moderna assusta professores de Ciências, ainda mais quando se observa a crescente popularização de temas de Genética Molecular, desde filmes e novelas, a testes de paternidade dramatizados em programas de televisão. Por sua vez, a temática do meio ambiente é constantemente abordada em jornais, revistas, televisão e internet, o que aguça a curiosidade dos alunos do ensino fundamental. Esses assuntos têm sido temas de eventos de extensão organizados pela 
UFPE, os quais contam com a participação de professores de Ciências.

\section{Considerações finais}

Nossa pesquisa teve como ponto de partida a necessidade de maior interação entre os cursos de Licenciatura oferecidos nas universidades públicas locais e a realidade das escolas públicas. Acreditamos que para o êxito na aprendizagem dos alunos e na metodologia adotada pelo educador, seria necessário

Efetivar uma prática pedagógica diferenciada, promovendo o atendimento às diferentes necessidades dos alunos; utilizar técnicas e instrumentos de avaliação da aprendizagem que dêem mais liberdade aos alunos para revelarem seus avanços e suas dificuldades e, conseqüentemente, reorientar e implementar o processo didático; estabelecer pequenas metas a serem alcançadas - que contemplem a formação da competência e habilidades essenciais aos novos tempos - que possam desencadear ações que tenham por perspectivas utopias fundamentadas na prática de uma escola pública verdadeiramente mais democrática. (PEREIRA; SOUZA, 2004, p. 204).
Ouvir as percepções e anseios dos professores do ensino básico é o primeiro passo para que a universidade cumpra sua função de pólo gerador de conhecimento aplicado à comunidade. É injusto responsabilizar apenas os docentes por eventuais falhas na qualidade da escola pública. Mudanças recentes nas relações de "poder" em sala de aula têm exposto professores a situações (muitas vezes constrangedoras) para as quais não estavam preparados. A falta de interesse de alunos - uma reclamação que pode ser repetida em todos os níveis, até em nível universitário desestimula o educador a ousar metodologias de ensino mais inovadoras e de avaliação mais criativas. Somente um processo em médio prazo de valoração do professor, que permita o investimento em pesquisa educacional, poderá gerar aprendizagem transformadora.

\section{Agradecimentos}

Agradecemos aos professores que se dispuseram a participar de nossa pesquisa, bem como aos diretores de escolas pelo apoio disponibilizado. À Prefeitura do Recife por seu apoio, interesse e autorização; a Emanuel Souto pela ajuda de campo. 


\section{Referências}

BARDIN, L. Análise de conteúdo. 3. ed. Lisboa: Editora 70, 2004.

BARROS, C.; PAULINO, W. R. Os seres vivos. 66. ed. São Paulo: Ática, 2002.

BAZZO, V. L. Para onde vão as licenciaturas?: a formação de professores e as políticas públicas. Educação, Santa Maria, RS, v. 25, n. 1, p. 53-65, 2000.

DIAS-DA-SILVA, M. H. G. F. O professor e seu desenvolvimento profissional: superando a concepção do algoz incompetente. Caderno CEDES, Campinas, SP, v. 19 n. 44, p. 33-45, 1998.

FRAZZON, L. M. O compromisso da Universidade com a formação continuada do professor. Revista Roteiro, Joaçaba, RS, v. 26, n. 46, p. 81-91, 2001.

HADJI, C. Avaliação desmistificada. Porto Alegre: ARTMED, 2001.

HOFFMANN, J. Avaliar para promover: as setas do caminho. 7. ed. Porto Alegre: Mediação, 2005.

HOLMESLAND, I. S. Qualidade e equidade no acesso ao conhecimento: experiências de uma sociedade igualitária. Educação, Porto Alegre, ano 26, n. 50, p. 45-70, 2003.

JESUS, S. N.; SOUZA J. C. V. Desenvolvimento profissional e motivação dos professores. Educação, Porto Alegre, ano 27, v. 1, n. 52, p. 39-58, 2004.

KRASILCHIK, M. Prática de ensino de biologia. 4. ed. São Paulo: Ed. da USP, p. 198, 2004.

KRUGER, V. Formação continuada de professores de ciências: o trabalho docente como referencia. Educação, Porto Alegre, ano 26, n. 51, p. 69-85, 2003.

LA LUZ, M.; SANTOS, M. T. Vivendo ciências. São Paulo: FTD, 2002.

LOGUERCIO, R. Q.; PINO, J. C. D.; SOUZA, D. O. G., A educação e o livro didático: implicações sociais. Educação, Porto Alegre, ano 25, n. 48, p. 183-193, 2002.

PEREIRA, L. C.; SOUZA, N. A. Concepção e prática de avaliação: um confronto necessário no ensino médio. Estudos em Avaliação Educacional: revista da Fundação Carlos Chagas, São Paulo, n. 29, p. 191-208, 2004.

SILVA, C. M. T.; AZEVEDO, N. S. N. O significado das tecnologias de informação para educadores. Ensaio: avaliação e políticas públicas em educação: revista da Fundação Cesgranrio, , v. 13, n. 46, p. 39-54, 2005. 
SOUTO, E. Intervenções alternativas e análise do material de apoio didático no ensino de zoologia. 2003. 53 f. Dissertação (Mestrado em Biologia Animal)-Universidade Federal de Pernambuco, Recife, 2003.

TEDESCO, J. C. Los nuevos desafíos de la formación docente. Revista de Tecnología Educativa, Santiago, Chile, v. 14, n. 3, p. 323-337, 2000.

VIANNA, D. M.; CARVALHO, A. M. P. Formação permanente: a necessidade da informação entre a ciência dos cientistas e a ciência da sala de aula. Ciência e Educação, São Paulo, v. 6, n. 1, p. 31-42, 2000.

Recebido em: 22/01/2005

Aceito para publicação em: 08/09/2006 


\section{APÊNDICE 1}

ROTEIRO DE ENTREVISTA - PERFIL DO PROFESSOR DE CIÊNCIAS DO RECIFE

I-) SOBRE O PROFESSOR:

1. Sexo: ( ) M ( ) F

3. Idade: ( ) até 25 anos

4. Formação acadêmica:
2. Instituição de ensino:

( ) 25 a 35

( ) 35 a 45

Ensino médio
Outra:

( ) Superior. Instituição, curso e ano de graduação

5. Há quantos anos ensina Ciências? ( ) <5 ( ) 5 a $10 \quad$ ( ) 10 a $15 \quad$ ( ) 15a $20 \quad$ ( )>20 Que série (s)? EF: ( ) $5^{a} \quad\left(\begin{array}{llllllll}6^{a} & (1) 7^{a} & (1) 8^{a} & \text { EM: } & (1) 1^{\circ} & (1) 2^{\circ} & (1) 3^{\circ}\end{array}\right.$

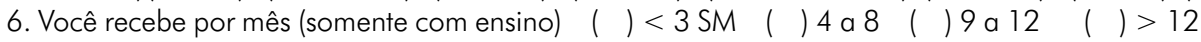

7. Ensina em mais de uma escola? ( ) não ( ) sim = ( ) só pública ( ) pública + particular

8. Tem fonte de renda adicional (não relativa a ensino) ? ( ) $\operatorname{sim}($ ) não

II) SOBRE FONTES DE INFORMAÇÃO EM CIÊNCIAS:

1. Costuma ler revista / periódico de divulgação cientifica? ( ) sim ( ) não.

Qualẹ( ) superinteressante ( ) Galileu ( ) Ciência Hoje ( ) Outros:

2. Caso negativo, por que não? ( ) custo ( ) falta de tempo ( ) outros:

3. Que livro(s) costuma consultar para tirar duvidas em Ciências?

4. Costuma freqüentar bibliotecas para se atualizar / tirar duvidas em Ciências? ( ) sim ( ) não

5. Tem acesso à Internet? ( ) sim ( ) não. Onde? ( ) casa ( ) escola ( ) outros

6. Utiliza a Internet para elaborar aulas ou pesquisar sobre Ciências? __ Caso negativo, por que não?

7. Sente dificuldade em encontrar material didático sobre biologia? ( ) sim ( ) não

Quais? ( ) custo dos livros ( ) ausência de biblioteca especializada ( ) falta de livrarias técnicas

( ) falta de tempo ( ) ausência de bons textos em português ( ) Outros:

III) SOBRE O ENSINO DE BIOLOGIA:

1. Você considera a carga horária de Ciências suficiente para cumprir o programa? ( ) sim ( ) não

2. Que recursos utiliza em sala de aula? ( ) livros ( ) vídeo ( ) slides ( ) transparências

( ) computador ( ) outros.

3. Que atividades extra-classe desenvolve? ( ) Feira de Ciências ( ) excursões ( ) experimentos

( ) visitas ( ) outros

4. Qual o livro / apostila de Ciências / Biologia é adotado pela escola?

5. Está satisfeito(a) com este material? ( ) sim ( ) não. por quê? (Comentários).

6. Que assunto de Ciências desperta mais interesse do aluno?

7. Que assunto de Biologia você tem mais dificuldade para ensinar? Por quê?

( ) Meio ambiente: Ar, Água, Solo ( ) Noções de Ecologia ( ) Seres Vivos: Animais

( ) Seres Vivos: Microorganismos ( ) Seres Vivos: Plantas ( ) Programa de Saúde

( ) Corpo Humano: Citologia e Histologia ( ) Corpo Humano: Reprodução e Genética

( ) Corpo Humano: Anatomia e Fisiologia ( ) Noções de Química ( ) Noções de Física.

8. Qual o seu método de avaliação da aprendizagem dos alunos?

( ) questões objetivas ( ) questões discursivas ( ) participação em atividades

( ) pesquisas ( ) seminários ( ) outros. Especificar

9. Que atividade / recurso mantidos na UFPE seriam mais úteis ao professor de Ciências?

( ) Coleções zoológicas ( ) manutenção de animais e plantas vivos ( ) experimentotecas

( ) herbários ( ) cursos e palestras de atualização em Biologia ( ) laboratórios ( ) outros

10. Comentários adicionais. 